\title{
EM BUSCA DE NARRATIVAS DE DIVERSIDADE ${ }^{1}$
}

\section{Emerson Giumbelli ${ }^{2}$}

Meus comentários ao texto de Clara Mafra estão orientados pela preocupação em problematizar o tema da diversidade religiosa. Números, categorias, composiçóes e - como o texto acertadamente indica - narrativas fazem parte das formas pelas quais a diversidade é concebida e apresentada. Também fazem parte as imagens, sendo muito bem-vinda a sugestão da autora em favor do recurso a hologramas para melhor apreendermos as transformaçóes e configurações do campo religioso no Brasil a partir de dados do censo do IBGE de 2010. De minha parte, serei menos categórico na destituição dos mapas. Sobretudo, apostarei na produtividade dos vetores e linhas como metáforas interessantes, a partir dos quais tanto hologramas quanto mapas podem ser elaborados. Pensar com linhas evita procedimentos de totalização que mapas e hologramas geralmente implicam, sem negar sua eventual necessidade. Por isso mesmo é que aceitarei a sugestão de Clara e procederei alternando entre planos que podem ser imaginados como superfícies de um holograma.

O primeiro plano refere-se à produção dos dados e sua divulgação pelo IBGE. A existência de um item no formulário censitário sobre religião não deve ser banalizada. Compõe um debate acerca do próprio estatuto da religião, considerando sua relevância pública. Agências estatísticas oficiais de vários países não incluem perguntas sobre religião em suas pesquisas com a justificativa de que não se trata de algo importante, ou de que se trata de assunto da esfera privada. Nos países em que, como o Brasil, temos outra

1 Este texto, além de ser um comentário ao artigo de Clara Mafra, apresenta resultados do projeto de pesquisa Religião, Estado e sociedade: regulação do religioso em quatro países latino-americanos, apoiado por Edital Universal do CNPq. Entre os objetivos dessa pesquisa está acompanhar as repercussões do Censo de 2010. Isso explica a sua extensão talvez exagerada em se tratando de um comentário.

2 Professor da Universidade Federal do Rio Grande do Sul. Doutor em Antropologia Social. E-mail: emerson.giumbelli@yahoo.com.br

Debates do NER, Porto Alegre, ANo I4, N. 24, P. 59-75, JUl./DeZ. 2013 
situação, é importante mantermos um debate sobre as formas pelas quais a religião é incluída em estatísticas oficiais. O texto de Clara contribui para isso.

Gostaria de acrescentar dois ou três pontos. Deve-se lembrar que a pergunta constante do censo brasileiro privilegia a dimensão da identidade - a religião que o respondente assume como "sua". Essa formulação deixa de fora, por exemplo, a dimensão da prática e mesmo os modos de compreensão das identificações, envolvendo trajetos e crenças específicas. $\mathrm{O}$ privilégio à identidade implica em um viés que favorece o cristianismo, uma vez que - para recuperar os termos propostos por Brandão (1988) - evangélicos e, sobretudo, católicos, podem "ser sem participar", em contraste com a frequência a centros espíritas e casas afro-religiosas, nas quais é comum “participar sem ser”. Essa característica reforça a reivindicação de Clara acerca da importância de termos outras perguntas que nos deem acesso a novas dimensões do envolvimento das pessoas com a religião.

Como sabemos, a forma com a qual os dados são registrados no Censo deve respeitar as respostas espontâneas dos recenseados. Isso permite um registro bastante rico acerca das opçōes apresentadas pelas pessoas. Mas o procedimento não está imune a falhas, como mostra a reclassificação de católicos brasileiros como católicos romanos, comentada por Clara. Altmann (2012) aponta outro problema, dessa vez envolvendo os luteranos. As máquinas usadas para registrar as respostas ao censo estavam configuradas com a opção de preenchimento automático. Ou seja, a digitação das primeiras letras abria um conjunto de alternativas compatíveis. No caso dos luteranos, havia 48 nomes com essa palavra, mas nenhum referia-se à Igreja Evangélica de Confissão Luterana do Brasil. Os dois episódios demonstram que a capacitação dos recenseadores e as tecnologias utilizadas no recenseamento afetam, em alguma medida, a produção dos dados.

A apresentação dos resultados pelo IBGE passa pela distribuição dos dados em categorias. Como informa o texto de Clara, em 2000, foram usadas 144 categorias; em 2010, 66. Seria interessante saber as razões e especificações dessa redução. De todo modo, essa quantidade de categorias contrasta com a divulgação de outros anos, em que o número era menor (47 em 1991; apenas $10 \mathrm{em} \mathrm{1980).} \mathrm{O} \mathrm{uso} \mathrm{de} \mathrm{um} \mathrm{leque} \mathrm{extenso} \mathrm{pelo} \mathrm{IBGE} \mathrm{permite} \mathrm{leituras}$ 
que explorem a diversidade religiosa em relação a fatores sociodemográficos variados, como rendimento, escolaridade, faixas etárias, sexo, localização geográfica, etc. Ao mesmo tempo, números novamente menores são encontrados na divulgação dos principais resultados, que recorrem a algumas categorias básicas: católicos, evangélicos (às vezes desdobrados em de missão, pentecostais e, agora, não determinados), espiritas, religião a fro-brasileira, outras religiôes e sem religião. É basicamente essa segunda forma de divulgação que alimenta os principais comentários que compõem a repercussão do censo, como veremos em seguida.

Aqui, portanto, passo a um segundo plano, que se refere às repercussões sobre os dados acerca de religião no Censo IBGE 2010. A base para meus comentários são um conjunto de notícias, reportagens e entrevistas pesquisadas em duas fontes, além da consideração do dossiê que a IHU On-Line organizou a propósito daqueles dados e de registros em revistas de grande circulação. ${ }^{3}$ Antes de me dirigir a esse material, chamo a atenção, como faz Lopes (2012), para o modo como alguns resultados foram colocados à disposição nos websites de dois grandes jornais brasileiros. Ambos ofereceram aos seus leitores instrumentos de interação, que permitiam escolha entre distintas opções de apresentação dos dados. O Estado do São Paulo preparou gráficos e diagramas, enfocando diversas dimensões; $O$ Globo avança em sofisticação, sobretudo na parte que chama de Mapa das Religióes no Brasil, que permite a elaboração de indicadores, em várias escalas, a partir de dados referentes a cada município brasileiro, que representam a distribuição dos adeptos de diferentes religiōes, incluindo "umbanda e candomblé". Além disso, oferece infográficos interativos que traçam o perfil de vários grupos de adeptos religiosos. ${ }^{4}$

3 Os arquivos de registros foram constituídos a partir de duas fontes, consultadas em março de 2013. Primeiro, o site da CNBB (<http://www.cnbb.org.br/>) em sua seção de notícias. Segundo, busca de notícias no site Folha Gospel, que se apresenta como "um site cristão/ evangélico independente” (<http://folhagospel.com/>). A compilação de registros foi realizada por Jorge Scola, bolsista de iniciação científica no projeto de pesquisa do CNPq.

4 Ver, respectivamente, <http://estadaodados.com/html/religiao/> e <http://oglobo.globo. com/infograficos/censo-religiao/>. Acesso em: 15 maio 2013.

Debates do NER, Porto Alegre, Ano I4, N. 24, P. 59-75, JUl./Dez. 2013 
Alongo-me sobre o Mapa das Religióes, pois penso que ilustra pontos valiosos para a discussão que me interessa. $\mathrm{O}$ seu manejo produz como resultado mapas comparativos preenchidos por circunferências de distintas grandezas, cada uma delas correspondente a um município brasileiro. Essas grandezas são determinadas pela variação percentual do número de adeptos no interior de uma das cinco categorias disponíveis: católicos, evangélicos, espíritas, umbanda e candomblé e sem religião. $\mathrm{O}$ instrumento não permite que vejamos os adeptos de várias religiōes ao mesmo tempo. Isso, que poderia ser tomado apenas como uma limitação, viabiliza uma representação inusitada: tem-se, alternadamente, um Brasil católico, um Brasil evangélico, e assim por diante. Como as circunferências alcançam um tamanho semelhante (a maior delas para os católicos é similar à maior delas para os espíritas, por exemplo), a principal diferença entre o Brasil católico e o Brasil espírita é a distribuição das circunferências. Além de nos levar a visualizar mais claramente aspectos da diversidade religiosa, esses mapas, formados por pontos que parecem se projetar para o alto, lembram exatamente os hologramas imaginados por Clara.

Enquanto essa apresentação de $O$ Globo permite visualizações em muitas escalas e planos, a divulgação e o comentário acerca dos resultados do censo cerram coro basicamente em torno do anúncio que conjuga "declínio católico, ascensão evangélica". Vale destacar a matéria da revista Exame On-Line, cuja manchete marca: "Católicos deixarão de ser maioria no Brasil em 2030". Assim inicia: "Pesquisadores acreditam que, até 2030, as filiações católicas serão menos de $50 \%$ da população brasileira. Em 2040, pelas projeçôes, católicos e evangélicos estariam empatados.” E continua:

Dados do IBGE mostram que, a partir de 1970, o catolicismo começou a não acompanhar o ritmo de crescimento da população, ao mesmo tempo em que correntes evangélicas se expandiam à medida que cresciam periferias e formavam-se novos municípios. A partir de 1991, esse processo se deu de forma mais acelerada, a ponto de, na última década, ser registrada a primeira perda real - em números totais - de católicos no Brasil. ${ }^{5}$

5 Cf. <http://folhagospel.com/modules/news/article.php?storyid=22684\&keywords=ce nso+2010>. Acesso em: 15 maio 2013.

Debates do NER, Porto Alegre, ANo I4, N. 24, P. 59-75, JUl./DeZ. 2013 
Fazendo companhia a essa profecia, a constatação, registrada em uma publicação evangélica: "Brasil: um país mais crente". A mesma matéria termina com a observação de que "Entre os países com maior presença evangélica em números absolutos, o Brasil aparece em $3^{\circ}$ lugar" . 6

De fato, o contraste entre descenso católico e crescimento evangélico marca a tônica da divulgação dos dados do IBGE. O próprio IBGE, nos comentários que elaborou para acompanhar a publicização do Censo, bateu nessa tecla. ${ }^{7}$ As notícias de jornais e revistas e as perguntas dirigidas a especialistas estiveram predominantemente orientadas pela mesma constatação. Um exemplo é a entrevista realizada pelo UOL/Folha de São Paulo, em julho de 2012, com o secretário geral da Confederação Nacional dos Bispos do Brasil (CNBB), que compreende várias perguntas baseadas nos dados recémdivulgados pelo IBGE. Outros assuntos, mesmo em períodos posteriores, forneceram novas ocasiões para comentários acerca do censo: a preparação da Jornada Mundial da Juventude e sucessão no Vaticano. O jornal New York Times preparou uma reportagem divulgada durante a vacância da Sé, atribuindo a um cardeal brasileiro a frase: "Nos perguntamos com ansiedade: por quanto tempo o Brasil continuará a ser um país católico?”. ${ }^{8}$ Voltemos, porém, à entrevista com um dos líderes da CNBB. Leonardo Steiner, bispo auxiliar de Brasília, procura relativizar os resultados lembrando que se trata de uma amostra e é confrontado pelo jornalista - "Então, em certa medida, tem uma metodologia que vem sendo seguida há décadas e a expectativa, segundo os dados projetados pelo censo, é que talvez em 20 ou 30 anos a maioria dos brasileiros tenha preferência pelas religiōes evangélicas".?

6 Cf. <http://folhagospel.com/modules/news/article.php?storyid=23002\&keywords=ce nso+2010>. Acesso em: 15 maio 2013.

7 Censo 2010: número de católicos cai e aumenta o de evangélicos, espíritas e sem religiāo, cf. <http://saladeimprensa.ibge.gov.br/noticias?view=noticia\&id=1\&busca=1\&idnot icia $=2170>$. Acesso em: 15 maio 2013.

8 Cf. <http://folhagospel.com/modules/news/article.php? storyid=24585\&keywords=ce nso+2010>. Acesso em: 15 maio 2013.

9 Cf. <http://www.cnbb.org.br/site/imprensa/noticias/9865-dom-leonardo-concedeentrevista-a-folha-de-sao-paulo>. Acesso em: 10 maio 2013.

Debates do NER, Porto Alegre, Ano I4, N. 24, P. 59-75, JUl./Dez. 2013 
Notamos que a defesa da credibilidade dos dados do IBGE que apontam o declínio do número de católicos vem acompanhada de projeção semelhante a que vimos acima acerca da ascensão evangélica.

Várias matérias, em jornais e revistas, repercutem e ampliam a notícia do crescimento evangélico. "População católica encolhe no Brasil. Evangélicos avançam", foi a manchete da revista Veja. ${ }^{10} \mathrm{O}$ site da revista Exame, em 2013, elaborou, a partir dos dados do IBGE, o que apresentou como um "ranking de capitais evangélicas”. Outra matéria explora estatísticas que mostram o aumento de pessoas identificadas com igrejas evangélicas na população indígena do Brasil. ${ }^{11}$ Em outros casos, os dados sobre afiliação religiosa oferecem a oportunidade para temas de natureza distinta, mas sempre relacionados com a presença dos evangélicos. A revista Forbes divulgou o patrimônio de líderes evangélicos no Brasil. Duas reportagens trabalham com as relações entre religião e política - mais especificamente, as eleições municipais em São Paulo no decorrer de 2012 - focadas totalmente no envolvimento de evangélicos e vinculando esse envolvimento com os dados do Censo. ${ }^{12} \mathrm{~A}$ revista Carta Capital elaborou duas grandes reportagens, anunciadas em suas capas, uma com aspectos variados acerca do crescimento evangélico, outra questionando a atuação política das chamadas "bancadas evangélicas". ${ }^{13}$ Assim, o bordão do crescimento evangélico dissemina-se, trazendo consigo a imagem de uma expansão em muitos campos da sociedade brasileira.

É verdade que, nos comentários e entrevistas, aparecem observações sobre secularização, secularismo e ateísmo, em contraponto com os temas

${ }^{10}$ Cf. <http://veja.abril.com.br/noticia/brasil/ibge-populacao-catolica-encolhe-no-brasil>. Acesso em: 10 maio 2013.

11 Cf., respectivamente, <http://folhagospel.com/modules/news/article.php?storyid=246 95\&keywords=censo $+2010>$ e $<$ http://folhagospel.com/modules/news/article.php?sto ryid $=22898 \&$ keywords $=$ censo $+2010>$. Acesso em: 15 maio 2013.

12 Cf., respectivamente, <http://folhagospel.com/modules/news/article.php?storyid=243 45\&keywords=censo+2010>, <http://folhagospel.com/modules/news/article.php?stor yid=22798\&keywords=censo $+2010>$ e $<$ http://folhagospel.com/modules/news/article. php?storyid=23543\&keywords=censo $+2010>$. Acesso em: 15 maio 2013 .

13 Cf., respectivamente, n. 707, 25 jun. 2012 e n. 745, 17 abr. 2013.

Debates do NER, Porto Alegre, ANo I4, N. 24, P. 59-75, JUl./DeZ. 2013 
anteriores. Diversidade, transformação, pluralismo e trânsito são também palavras-chaves na repercussão do censo, mas muito comumente esses termos são usados para traduzir a constatação mais geral sobre católicos e evangélicos. Isso não deixa de ser confirmado quando as constataçóes se invertem. No âmbito da CNBB, a discussão sobre os resultados do censo em 2012 foi conjugada com a divulgação de dados do CERIS (Centro de Estatísticas Religiosas e Investigação Social) acerca do número de paróquias e religiosos católicos. A ascensão nesses números motivou comentários otimistas por parte de porta-vozes eclesiásticos, uma vez que apontariam, segundo eles, para uma Igreja mais estruturada e em franca expansão. ${ }^{14}$ Ao mesmo tempo, vários analistas, e não apenas ligados à Igreja Católica, apontaram a menor expansão dos evangélicos (em comparação com a década anterior) e mesmo o decréscimo do número de adeptos da Igreja Universal do Reino de Deus, denominação que esteve há bastante tempo associada, na cobertura midiática e nas pesquisas acadêmicas, à vanguarda evangélica (Campos, 2012; Mattos, 2012). ${ }^{15}$

Outra maneira de continuar a sistematização das reações aos dados do Censo é buscando focar sobre diferentes segmentos do campo religioso. Já vimos alguns dos comentários de porta-vozes da Igreja Católica no Brasil. Vale ainda mencionar uma forma de argumentação que me parece interessante, pois conjuga em si duas possibilidades de leituras que podem aparecer como opostas. Essa argumentação reconhece a pluralização da sociedade brasileira, muito comumente entendida como desafio, seja no plano intelectual, seja no plano dos imperativos missionários. Ao mesmo tempo, vemos a insistênciaembora seja também preciso ver isso como uma transformação do lugar da Igreja Católica, não mais sustentada como representante de uma totalidade (Giumbelli, 2006) - no caráter majoritário do catolicismo. Um artigo do Arcebispo de Belo Horizonte, Dom Walmor Oliveira de Azevedo, sugere que

${ }^{14}$ Por exemplo, <http://www.cnbb.org.br/site/imprensa/noticias/9711-ibge-divulga-dadosceris-mostra-qigreja-vivaq>.

15 No caso dos porta-vozes católicos, ver entrevista já mencionada: <http://www.cnbb. org.br/site/imprensa/noticias/9865-dom-leonardo-concede-entrevista-a-folha-de-saopaulo>. Acesso em: 10 maio 2013

Debates do NER, Porto Alegre, Ano I4, N. 24, P. 59-75, JUl./Dez. 2013 
ocorra uma leitura "qualitativa" dos números, na medida em que se trata de avaliar a qualidade da religiosidade que mais cresce. Quanto ao catolicismo:

[...] a Conferência Nacional doa Bispos do Brasil (CNBB), no dia em que o IBGE divulgou o Censo 2010, apresentou resultados de um estudo produzido pelo Centro de Estatísticas Religiosas e Investigação Social (CERIS) - entidade brasileira de pesquisa religiosa fundada pela própria $\mathrm{CNBB}$. Esse trabalho mostra que a Igreja Católica não apenas continua majoritária na sociedade brasileira, reunindo $64,6 \%$ da população, como também cresceu vertiginosamente em número de paróquias e dioceses, vocaçóes, na efervescência de novos movimentos eclesiais e nos investimentos na rede de comunidades. ${ }^{16}$

Acerca dos evangélicos, não recorro a visões externadas por porta-vozes institucionais, o que significaria percorrer um universo enorme de possibilidades; teço algumas considerações tendo como base as notícias veiculadas no Portal Folha Gospel. De todo modo, chamam atenção as poucas ocorrências de celebrações ufanistas sobre os dados do IBGE. Uma exceção é uma matéria publicada na revista assembleiana Mensageiro da Paz, que destaca a força mundial do pentecostalismo, projetando um crescimento expressivo de seus fieis. ${ }^{17} \mathrm{Na}$ direção oposta, encontrei um comentário que contrasta a ascensão do número de evangélicos com a persistência da desigualdade social no Brasil. ${ }^{18}$ Há outras ocorrências em que evangélicos reagem criticamente ao próprio crescimento, como é o caso de comentários dirigidos aos números da Igreja Mundial do Poder de Deus. Tais comentários explicitam as tensões que percorrem o universo evangélico e o descompasso que existe entre êxito institucional e (i)legitimidade social. Nessa chave, é importante notar o contraste entre os dois arquivos de notícias. $\mathrm{O}$ arquivo relativo à $\mathrm{CNBB}$ traz basicamente órgãos e porta-vozes vinculados à Igreja Católica. $\mathrm{O}$ arquivo relativo à Folha Gospel raramente abrange registros de posicionamentos pentecostais, predominando análises de intelectuais não ligados a igrejas ou

${ }^{16}$ Cf. <http://www.cnbb.org.br/site/articulistas/dom-walmor-oliveira-de-azevedo/9758censo-e-religiosidade>. Acesso em: 15 maio 2013.

17 Cf. <http://folhagospel.com/modules/news/article.php?storyid=24235\&keywords=ce nso+2010>. Acesso em: 15 maio 2013.

${ }^{18}$ Cf. <http://colunas.gospelmais.com.br/explosao-evangelica-somos-42-milhoes-e-dai_1126.html>. Acesso em: 10 maio 2013.

Debates do NER, Porto Alegre, ANo I4, N. 24, P. 59-75, JUl./DeZ. 2013 
associados a denominações históricas. Mais precisamente, no universo de 27 registros, apenas em três aparecem declaraçôes de religiosos pentecostais. Em suma: a autoridade dos católicos de falarem sobre si e sobre os demais não é reconhecida aos pentecostais.

Foram encontrados poucos registros de pronunciamentos de lideranças ligadas ao universo espírita e afro-brasileiro. A Federação Espírita Brasileira - que parece ter se empenhado em incrementar as formas de registro dos adeptos do espiritismo (Lewgoy, 2012) - comentou o crescimento de seus números em uma perspectiva de aprimoramento da organização interna. Um dos pais de santo mais politicamente ativos em Porto Alegre - capital do estado que despontou como o mais afro-religioso nos dados do IBGE - converteu tais dados em convite para uma marcha contra a intolerância religiosa em janeiro de 2013, pois os resultados obrigam [...] a sair dos números das pesquisas e nos materializarmos no espaço público e nas Ruas". ${ }^{19}$ Assim, enquanto os espíritas tomam os números do censo como oportunidade para aprimoramentos pastorais, os afro-religiosos miram as ruas como esfera de manifestação - o que expressa algo sobre as distintas formas de presença dessas religiōes na sociedade brasileira.

Creio que faz sentido imaginar esses diferentes modos de apresentação e de leitura dos dados do IBGE como linhas que se distribuem por distintas superfícies. Juntas, linhas e superfícies, ora paralelas, ora cruzadas, formam mapas ou hologramas possíveis. Mapas e hologramas, por sua vez, sugerem cortes e recortes que podem também ser úteis para acessarmos as várias dimensões e planos que o mesmo conjunto de dados instaura. Parece-me que é possível conciliar essa imagem com o holograma proposto por Clara, "[...] formado por muitas versóes de cristianismo com focos de outras religiosidades".

Uma das linhas cuja distribuição gostaria de acompanhar é a sugerida pelo termo tradição. Apresso-me a esclarecer que, em meus comentários, tradição não é o oposto da modernidade; sobretudo, não é a reiteração do

19 Para o primeiro, ver <http://www.febnet.org.br/blog/geral/noticias/censo-religioso-ibge-2010/>; para o segundo, ver <http://www.babadybadeyemonja.com/2012/12/ convite-marcha-2013.html $>$. Ambos os registros foram encontrados por Jorge Scola. Acesso em: 20 mar. 2013.

Debates do NER, Porto Alegre, ANo I4, N. 24, P. 59-75, JUl./DeZ. 2013 
passado, e sim um componente do presente. Se a tradição aponta necessariamente para o passado, é sempre graças a uma recomposição que considera as condições e exigências do presente. Nesse sentido, recorrer à ideia de destradicionalização não significa o fim das tradições, e sim sua recomposição sob a constatação de alguma forma de continuidade no presente.

Alguns dados do Censo de 2010 confirmam as tendências associadas a uma destradicionalização (Fernandes, 2012), com a estagnação ou decréscimo de respostas relativas a grupos de imigração (incluindo os budistas, segundo os comentários de Usarski, 2012) e afro-religiosos, sem falar, é claro, do número de católicos. Pode-se ainda mencionar, nessa chave, a criação, nos dados divulgados pelo IBGE, das categorias ateus e agnósticos. É importante relacionar esse novo registro às mobilizaçōes recentes que vêm ocorrendo no Brasil - na esteira de outros países - as quais buscam conferir maior legitimidade e visibilidade a essas identificaçoes. ${ }^{20}$ Ao mesmo tempo, a especificação de ateus e agnósticos como parcela do contingente dos sem religiāo levanta um dilema interpretativo acerca destes últimos: deve-se vê-los como parte do universo religioso - parece-me que os comentários de Clara vão nessa direção - ou como recusa a essa participação?

Em relação aos vetores identificados diretamente com a tradição, lembro a análise que Camurça (2006) elaborou sobre os números do catolicismo no censo de 2000. Nela, o historiador e antropólogo chama nossa atenção para a relevância do número de católicos em Minas Gerais e nos estados do Sul e também para a força de expressões ligadas à Renovação Carismática. Isso significa reconhecer componentes de modernidade nas formas de presença dessa religião - o mesmo podendo ser afirmado, em outra escala, acerca do luteranismo. Gracino Júnior (2012) nota a relação do catolicismo com as políticas oficiais de patrimonializaçao, mais antigas e mais recentes. Se levarmos em conta as mais recentes, devemos destacar seus efeitos sobre as religiōes afro-brasileiras, sobretudo as tidas como mais "tradicionais". Em suma, o decréscimo numérico que parece atingir os grupos tradicionais

${ }^{20}$ Ver, por exemplo, <http://folhagospel.com/modules/news/article.php?storyid=24657 \&keywords=censo+2010>. Acesso em: 15 mar. 2013.

Debates do NER, Porto Alegre, ANo I4, N. 24, P. 59-75, JUl./DeZ. 2013 
tem como contrapartida movimentos e processos que operam no sentido de algum fortalecimento.

Os dados de 2010 destacam ainda o crescimento dos evangélicos assembleianos. A religiosidade assembleiana é identificada em parte da literatura como um "pentecostalismo tradicional", ou "clássico". Provavelmente as razôes para seu crescimento conjugam a reiteração de características que sustentam tal tradicionalidade com a assimilação de formas de religiosidade que Clara, em seu comentário, associa com o impacto devido aos êxitos da IURD (ver também Matos, 2012). Isso corresponde ao que outros identificam como uma neopentecostalização do universo evangélico - e não apenas dele. Tal processo convive, para ficarmos na formulação de Clara, com "[...] as convençôes estabelecidas a partir de uma cultura católica de longa duração". Dois trabalhos recentes que tive a oportunidade de orientar tratam de universos nos quais o pentecostalismo, quando não está ausente, é objeto de reiteradas suspeitas. ${ }^{21}$

Por fim, gostaria de avançar percorrendo outra das linhas que se distribuem no espaço, uma interpretação sobre o número que talvez tenha sido o principal destaque nos dados do censo de 2010: o de evangélicos não determinados $^{22}$. Trata-se de um número expressivo, maior do que a soma de todos os adeptos declarados de igrejas evangélicas de missão e bastante superior ao seu correspondente no censo anterior. Pode-se afirmar que são duas as principais leituras sobre esse dado em comentários já publicados. A primeira tenta explicar o número aceitando que se trata de uma medida correta; e o que esse dado mede é explicado por um processo de desinstitucionalização, algo presente mais amplamente na realidade e que agora atinge o universo evangélico. Ou seja, o número capta com alguma exatidão um contingente de evangélicos que não pertence a denominações específicas ou cujo pertencimento é atenuado por trânsitos e desafiliaçôes mais ou menos

21 Renan Santos (2013) realizou etnografias de aulas de ensino religioso em escolas públicas de Porto Alegre; Norberto Decker (2013) acompanhou atividades do Conselho Municipal de Assistência Social de Porto Alegre.

22 Desenvolvo aqui um raciocínio já anunciado em Giumbelli (2012).

Debates do NER, Porto Alegre, Ano I4, N. 24, P. 59-75, JUl./Dez. 2013 
constantes. A segunda leitura atribui o dado a um problema do instrumento de mensuração. Nesse caso, se aposta que uma outra pergunta - por exemplo, "evangélico de qual denominação?" - diminuiria significativamente o número de evangélicos não determinados.

Como exemplos da primeira leitura, podemos apontar Mariano (2012) - que nota a expansão da privatização religiosa -, Campos (2012) - que aponta evangélicos menos afeitos a estruturas burocráticas e que limitam sua frequência aos templos, preferindo às vezes as paróquias virtuais -, Oliveira (2012) - que suspeita a existência de evangélicos não praticantes e em igrejas novíssimas, Vital (2012) - que se refere a um grande fluxo de entrada e saída das igrejas evangélicas. Para a segunda leitura, podemos nos remeter ao mesmo comentário de Mariano, que sinaliza para "limitações do censo". Com ele concorda Mariz (2012): "A hipótese mais plausível é que tenha sido problema na coleta dos dados. Dessa forma, ficamos sem informação da denominação de um percentual significativo de evangélicos".

Minha interpretação da significância do número de evangélicos sem instituição determinada, parte de uma anuência com as duas leituras anteriores. Se houvesse uma segunda pergunta, como complemento da que consta do formulário atual, penso que uma parcela das respostas indicaria alguma denominação e penso também que haveria outra parcela (provavelmente menor que a primeira) que confirmaria a flutuação institucional. Mas o que não deve deixar de nos intrigar é a existência desse número. Duas considerações são fundamentais. Primeiro, não houve mudança no instrumento de mensuração entre os dois últimos censos; o que mudou foi a magnitude do número. Então, o que levou tantos evangélicos a não apontarem uma denominação específica para sua identificação? Segundo, pelo que sabemos através de diversas pesquisas sobre o universo evangélico, não faz sentido a existência de um contingente tão grande de pessoas que não seriam capazes de apontar um pertencimento denominacional, mesmo sob um vínculo atenuado ou intermitente.

Parece-me, portanto, que para entender a força do número dos evangélicos sem instituição determinada, precisamos dar a devida atenção à categoria evangélico. Junto com o crescimento do número de evangélicos,

Debates do NER, Porto Alegre, ANo I4, N. 24, P. 59-75, JUl./DeZ. 2013 
houve o fortalecimento da própria categoria genérica. É isso, a meu ver, que ajuda a entender a magnitude do número. Em 2010, mais do que em décadas anteriores, milhões de pessoas encontraram plausibilidade em responder à pergunta "qual é sua religião?" dizendo apenas evangélico, mesmo que pertencessem a alguma denominação específica. Se antes, em se tratando de identificação, apontar uma igreja era praticamente imprescindível, agora, para muitos, passa a ser suficiente - e isso é uma medida do grau de realidade da categoria - recorrer ao genérico da identidade, ao coletivo das denominaçóes.

Embora não me pareça que nenhum comentarista tenha articulado o argumento que apresento aqui, com certeza vários apontam para processos que ajudam a entender as razões pelas quais a categoria evangélico adquiriu tal consistência. Mariz (2012), na mesma entrevista em que aponta problemas na coleta dos dados, refere-se a campanhas políticas e eventos interdenominacionais como momentos de construção de uma identidade evangélica única. Sanchis (2012) aponta a importância do que chama de misticismo sonoro, ao qual também podemos relacionar à formação de uma identidade genérica. Em chave similar, Clara, em seu texto, aponta os efeitos da internet, de eventos transnacionais, da produção e consumo do gospel e do turismo religioso, que atraem evangélicos em busca de "[...] experiências religiosas mais plurais dentro de um espectro considerado cristão". De minha parte, reforçaria a importância que nessa produção desempenharam importantes lideranças e igrejas pentecostais, que envolvem a defesa da "liberdade religiosa”, como tentei demonstrar em outros textos (Giumbelli, 2002, 2003, 2008). Líderes, representantes políticos e expressões midiáticas vinculadas à IURD, mesmo sem contar com qualquer delegação, afirmam atuar em nome de todos os evangélicos em suas disputas e conquistas. Se aceitamos o argumento de Clara sobre a importância da IURD para esse contingente de evangélicos não determinados, não deixa de ser irônico que seu crescimento ocorra agora às expensas dos adeptos declaradamente iurdianos.

Em suma, se a divulgação dos dados do Censo de 2010 acerca de afiliação religiosa teve como tônica a díade declínio católico / ascensão evangélica, a narrativa que procuro subscrever busca destacar algumas

Debates do NER, Porto Alegre, Ano I4, N. 24, P. 59-75, JUl./Dez. 2013 
formas de seguir a diversidade. Elas podem ser exercitadas em determinadas imagens disponíveis para apresentar os dados. Podem ser encontradas em vários modos pelos quais a tradição se reitera e se desmancha. Podem mesmo ser confirmadas no argumento que destaca a consolidação do evangélico genérico nos números do IBGE, figura que não se opõe necessariamente à heterogeneidade de seu universo religioso e à proliferação de pequenas denominações. ${ }^{23}$ Se o evangélico genérico pode fornecer o caminho para a construção de novas hegemonias (em disputa ou em aliança com o catolicismo), ele instaura também, na medida em que não constitui simplesmente o resultado da soma de todas as denominações, a presença de uma nova agência no campo religioso e na sociedade brasileira.

\section{REFERÊNCIAS}

ALTMANN, Walter. Censo IBGE 2010 e Religião. Horizonte, v. 10, 2012. Disponível em: <http://periodicos.pucminas.br/index.php/horizonte/ article/view/P.2175-5841.2012v10n28p1122>. Acesso em: 30 maio 2013.

BRANDÃO, Carlos Rodrigues. Ser católico: dimensões brasileiras - um estudo sobre a atribuição de identidade através da religião. In: SACHS, Viola (Org.). Brasil \& EUA: religião e identidade nacional. Rio de Janeiro: Graal, 1988.

CAMPOS, Leonildo Silveira. "Rebanho virtual", fator que contribui para o individualismo religioso evangélico? (entrevista). Revista IHU On-Line, n. 400, 27 ago. 2012. Disponível em: <http://www.ihuonline.unisinos.br/ index.php?option $=$ com_content $\& v i e w=$ article $\& i d=4592 \&$ secao $=400>$. Acesso em: 30 maio 2013.

CAMURÇA, Marcelo. A realidade das religiōes no Brasil no Censo IBGE2000. In: TEIXEIRA, Faustino; MENEZES, Renata (Orgs.). As religiōes no Brasil - continuidades e rupturas. Petrópolis: Vozes, 2006.

23 Sobre o primeiro aspecto, ver Menezes (2012); sobre o segundo, a interessante reportagem do jornal O Estado de São Paulo. Disponível em: <http://folhagospel.com/modules/ news/article.php? storyid $=22729 \&$ keywords $=$ censo $+2010>$.

Debates do NER, Porto Alegre, ANo I4, N. 24, P. 59-75, JUl./DEZ. 2013 
DECKER, Norberto. Quem Aprova, Levante A Mão: Um Estudo Antropológico das Relações entre Religião e Políticas Públicas desde o Conselho Municipal de Assistência Social de Porto Alegre (RS). Dissertação (Mestrado em Antropologia Social) - Instituto de Filosofia e Ciências Humanas, Universidade Federal do Rio Grande do Sul, Porto Alegre, 2013.

FERNANDES, Sílvia. A (re)construção da identidade religiosa inclui dupla ou tripla pertença (entrevista). Revista IHU On-Line, 2012. Disponível em: <http:// bit.ly/RBr97a $>$. Acesso em: 30 maio 2013.

GIUMBELLI, Emerson. Censo 2010 evidencia uma tensão entre hegemonia e diversidade (entrevista). Revista IHU On-Line, 2012. Disponível em: <http://www.ihu.unisinos.br/entrevistas/515515-censo-2010-evidenciauma-tensao-entrevista-especial-com-emerson-alessandro-giumbe>. Acesso em: 30 maio 2013.

- A Presença do Religioso no Espaço Público: Modalidades no Brasil. Religião \& Sociedade, v. 28, n. 2, p. 80-101, 2008.

Minorias religiosas. In: TEIXEIRA, Faustino; MENEZES, Renata (Orgs.). As religióes no Brasil - continuidades e rupturas. Petrópolis: Vozes, 2006.

. Liberdade Religiosa no Brasil Contemporâneo: Uma Discussão a partir do Caso da Igreja Universal do Reino de Deus. In: ABA (Org.). Antropologia e Direitos Humanos. Niterói: EDUFF, 2003.

. O Fim da Religião: dilemas da liberdade religiosa no Brasil e na França. São Paulo: Attar, 2002.

GRACINO Junior, Paulo. A visão aérea e a do nadador: reflexões sobre católicos e pentecostais no censo de 2010. Horizonte, v. 10, 2012. Disponível em: <http://periodicos.pucminas.br/index.php/horizonte/article/ view/P.2175-5841.2012v10n28p1154>. Acesso em: 30 maio 2013.

LEWGOY, Bernardo. Espiritismo, religião do meio (entrevista). Revista IHU On-Line, n. 400, 27 ago. 2012. Disponível em: <http://www.ihuonline. 
unisinos.br/index.php?option $=$ com_content $\&$ view $=$ article $\&$ id $=4594 \& \mathrm{~s}$ ecao $=400>$. Acesso em: 30 maio 2013.

LOPES, José Rogério. As religiōes segundo os dados do Censo 2010: desafios e perspectivas (entrevista). Revista IHU On-Line, n. 400, 27 ago. 2012. Disponível em: <http://www.ihuonline.unisinos.br/index. php?option $=$ com_content $\& v i e w=$ article $\& i d=4590 \&$ secao $=400>$. Acesso em: 30 maio 2013.

MARIANO, Ricardo. Em marcha, a transformação da demografia religiosa do país. Folha de São Paulo, São Paulo, 30 jul. 2012.

MARIZ, Cecília. Pentecostalismo: mudança do significado de ter religião (entrevista). Revista IHU On-Line, n. 400, 27 ago. 2012. Disponível em: $<$ http://www.ihuonline.unisinos.br/index.php?option=com_content\&view $=\operatorname{article} \& i d=4591 \&$ secao $=400>$. Acesso em: 30 maio 2013 .

MATTOS, Paulo Ayres. A relevante queda do crescimento evangélico revelado pelo Censo 2010 (entrevista). Revista IHU On-Line, 2012. Disponível em: <http://bit.ly/NsbbKk>. Acesso em: 30 maio 2013.

MENEZES, Renata. Censo 2010, fotografia panorâmica da vida nacional (entrevista). Revista IHU On-Line, n. 400, 27 ago. 2012. Disponível em: <http://www.ihuonline.unisinos.br/index.php?option=com_content\&view $=\operatorname{article} \& \mathrm{id}=4588 \&$ secao $=400>$. Acesso em: 30 maio 2013 .

OLIVEIRA, Pedro Ribeiro de. A desafeição religiosa de jovens e adolescentes (entrevista). Revista IHU On-Line, 5 jul. 2012. Disponível em: <http://bit. ly/NaDG0k>. Acesso em: 30 maio 2013.

SANCHIS, Pierre. Pluralismo, transformação, emergência do indivíduo e de suas escolhas (entrevista). Revista IHU On-Line, n. 400, 27 ago. 2012. Disponível em: <http://www.ihuonline.unisinos.br/index.php?option=com_cont ent\&view $=$ article $\& i d=4586 \&$ secao $=400>$. Acesso em: 30 maio 2013.

SANTOS, Renan. Religiāo é igual, religiāo é diferente: reflexões a partir do ensino religioso nas escolas públicas de Porto Alegre. Dissertação (Mestrado 
em Antropologia Social) - Instituto de Filosofia e Ciências Humanas, Universidade Federal do Rio Grande do Sul, Porto Alegre, 2013.

USARSKI, Frank. O budismo étnico está gradativamente envelhecendo (entrevista). Revista IHU On-Line, n. 400, 27 ago. 2012. Disponível em: $<$ http://www.ihuonline.unisinos.br/index.php?option=com_content\&view $=$ article\&id $=4595 \&$ secao $=400>$. Acesso em: 30 maio 2013 .

VITAL, Christina. Protestantismo à brasileira (entrevista). Carta Capital, versão on-line, 2012. Disponível em: <http://www.cartacapital.com.br/sociedade/ protestantismo-a-brasileira>. Acesso em: 30 maio 2013. 